\title{
The Dynamics of Knowledge Sharing in the Biotechnology Industry: An Indian Perspective Tripurasundari Joshi
}

\author{
" Coming together is a beginning, staying together") \\ is progress, and working together is success. \\ Edward Everett Hale (1822-1909) \\ Author, historian, and minister
}

\begin{abstract}
The role of biotechnology in providing an alternate, more productive approach to new drug development is well accepted globally. Multinational pharmaceutical companies have begun outsourcing product development and its clinical validation to biotechnology firms in India. The sector in India has also witnessed the entry of startups in various phases of the drug development value chain. Technological innovation is a key growth driver in the "bio pharma" vertical in recognition of which numerous alliances are seen in the sector in India. These alliances have put in place a structure for technological learning to happen, which is necessary for innovation. However, the nature of knowledge in biotechnology, in large measure, is both tacit and complex. Such knowledge is difficult to transfer. At the same time, transferability of knowledge is critical to developing technological capability, which in turn can facilitate the technological innovations that are crucial for the growth of the sector in India. The current research is motivated by the question of how the firms in this sector deal with this paradox. An exploratory approach is adopted to understand the practices of knowledge sharing as well as its perceived impediments at the firm level in the Indian context.
\end{abstract}

\section{Introduction}

Globally, new drug development has been the responsibility of pharmaceutical companies with deep knowledge in organic and synthetic chemistry. The cost of developing a new drug based on this chemical route is somewhere between $\$ 600$ million and $\$ 1$ billion CAD (Dickson \& Gagnon, 2004). Also, it takes well over a decade to convert a drug candidate to a marketable product (Bains, 2004). The drug industry is plagued by low productivity, rising costs of product development, shorter product lifecycles, technology complexity and competitive pressures from generics.

Thus, there is a felt need in the pharmaceutical sector to develop more effective therapeutic agents at lesser cost. As a possible solution, pharmaceutical companies have started outsourcing both product development as well as its clinical validation to biotechnology firms. The biotechnology firms use approaches to drug development that are based on life sciences, which represents a paradigm shift in technical know-how. The discovery and development of drugs through biotechnological methods is an evidence-based approach (Keller, 2001; Miller, 2002) resulting in better productivity. Essentially the "pharma bio" vertical is heavily dependent on technological innovation for survival and growth. In keeping with the multidisciplinary nature of the industry, firms enter into various forms of upstream, downstream, and horizontal alliances. These relationships are made with the expectation that technological capability would develop, which, in turn, would result in better technological innovation (Edwards et al., 2003).

The development of technological capability in a firm requires the continuous building and use of new product and process technology know-how. This is made possible by accessing and sharing knowledge between firms and within firms. A review of the literature about the biotechnology sector in India reveals that there is little documentation in the public domain 


\section{The Dynamics of Knowledge Sharing in the Biotechnology Industry: An Indian Perspective Tripurasundari Joshi}

about the state of knowledge sharing processes in biotechnology firms in India. Thus, this study adopts an exploratory approach to understand the firm-level practices of knowledge sharing and its perceived impediments within the Indian context.

\section{Overview of the Biotechnology Industry}

Drug development is a long and technically arduous process. In simple terms, it begins by locating a biomolecule that could become the means for blocking the progress of a specific disease. The initial efforts are in the identification of the appropriate biomolecule and certain compounds that can interact with the identified molecule and continue the blocking action. Then, the stages of animal and human testing begin. The new entity becomes a candidate drug once it enters the human clinical study stage. In three phases, the safety, dosage, and efficacy aspects are tested. The firm then would arrange for the drug approved and arrange to market it.

Biotechnology firms are intermediary links in the value chain for new drug development. Their goal is to transfer the technology know-how developed within their organizations to a larger entity (such as an established pharmaceutical company) with manufacturing and marketing muscle. Typically, three types of firms would be involved in the value chain: i) university or national laboratories, who would do the initial identification; ii) biotechnology firms, who may develop the prospective drug by establishing its dosage, safety, and efficacy; and, finally, iii) the pharmaceutical firms, who would obtain approval for the drug and market it. There could be variations in this basic scheme with some pharmaceutical companies involved in clinical testing, too, or for that matter some biotechnology firms involved in contract manufacturing. Biotechnology is a knowledgeintensive, high-tech industry, and the technologies involved are multidisciplinary in nature. As observed by Powell and colleagues (1996), "biotechnology is a competence destroying innovation based on immunology and molecular biology". It is essentially a disruptive technology.

Biotechnology processes are technically complex, requiring sophisticated analytical skills as well as an intuitive judgement in decision making (Aggrawal, 2007). This field presupposes deep skills in the people involved in a scientific project. These skills take many years to develop and hone. The know-how in this sector can be developed mainly through continuous inter- actions among the multiple specialized disciplines (Quinn, 2000). Projects in this sector can be categorized as high risk with high probability of failure at any stage in the value chain.

In spite of these challenges, the biotechnology sector has made a significant contribution in terms of a deeper molecular understanding of pathology, which in turn has supported the development of effective drugs and vaccines targeted to those diseases (Miller, 2002).

\section{Biotechnology in India}

In India, the total biotechnology investment in the country is estimated to be in excess of 187 billion INR (approximately $\$ 3.6$ billion CAD) (ABLE, 2017). According to the 2011 biotech industry survey produced by industry associations, the total industry turnover of the biotechnology sector in India was in the range of $\$ 4$ billion USD at that time (The Hindu, 2011). The industry in India is characterized by a shortage of qualified manpower, weak laboratory infrastructure, and a lack of access to scientific literature. Though these weaknesses have been acknowledged and corrective actions are being put in place, they have an impeding effect on overall innovation.

The Indian process patent regime brought in by The Patents Act, 1970 (IPI, 1970) led the way for reverse engineering of biomolecules from imported clones and manufacturing standard operating practices adopted from the developed markets. Because of this, Indian expertise in process development needs strengthening. Though Indian academia has played a robust role in transferring process development technologies to the industry, they have not made a serious impact. Besides, India is now a signatory to the Trade-Related Intellectual Property Rights (TRIPS) Agreement (https://en.wikipedia.org/wiki/TRIPS_Agreement), which means it will enforce product patents in all manufacturing sectors. With the re-engineering option no longer viable, manufacturers now have to develop their innovation capabilities. To this point, a major impediment to the growth of the sector has been an insufficient number of innovative companies to reach a critical mass (Frew et al., 2007)

\section{Technological Innovation and Learning in the Biotechnology Sector}

Given the high-tech, knowledge-intense nature of the industry, biotechnology innovations are by default 


\section{The Dynamics of Knowledge Sharing in the Biotechnology Industry: An Indian Perspective Tripurasundari Joshi}

technology led. Technological innovation is defined as "an organization's ability to enhance its technological innovativeness and create new customer value propositions by offering new products and services, adopting new technologies, or creating new skills and competencies" (Huang, 2011). Technological innovation can be manifested as new offerings, the adoption of new technologies, or creating new process know how. For a firm to sustainably develop technology innovations, the individuals within the firm have to develop technological capability. This can be built through the process of technological learning. The nature of technological innovation in biotechnology would include new drug identification and development capabilities as also clinical testing and regulatory compliance know how.

Technological learning is "the process by which a technology-driven firm creates, renews, and upgrades its latent and currently used capabilities based on its stock of explicit and tacit resources" (Carayannis, 2006). The resource-based view of firms regards technological learning and the subsequent building of technical competence as a core competence that can be hard to copy. Technological learning can be both external and internal. External learning involves learning from alliances with other firms. It expands a firm's knowledge base (Bierly III et al., 2009) and also reduces innovation time. Internal learning is a transfer of knowledge among individuals or firms. Both types of learning have a positive effect on the performance of organizations.

The biotechnology sector involves a lot of experimentation at the various stages in the value chain and provides many opportunities for developing deep skills with time. Repeated trials ensure learning and any interference with this process would hamper innovation by not allowing the integration and honing of technological learning (Harlow, 1949). Teece, Pisano, and Shuen (1997) refer to learning as both an individual and an organizational process.

\section{Absorptive Capacity and Knowledge Sharing in the Biotechnology Sector}

The concept of absorptive capacity relevant in the biotechnology sector. Cohen and Levinthal (1990) first introduced this concept as "the ability of a firm to recognize the value of new, external information, assimilate it, and apply it to commercial ends". Zahra and George (2002) further delineated the concept into potential and realized absorptive capacity. The former refers to "a firm's capability to identify and acquire ex- ternally generated knowledge that is critical to its operations" as well as "the firm's routines and processes that allow it to analyze, process, interpret and understand the information obtained from external sources" (Zahra \& George, 2002). The latter refers to a different skill which is "a firm's capability to develop and refine the routines that facilitate combining existing knowledge and the newly acquired and assimilated knowledge" as well as the "organizational capability based on the routines that allow firms to refine, extend, and leverage existing competencies or to create new ones by incorporating acquired and transformed knowledge into its operations" (Zahra \& George, 2002). Absorptive capacity develops incrementally in organizations and supports them in being more sensitive to new technology absorption opportunities in the environment. As Phene and colleagues (2006) put it, "when the knowledge base is diverse, it is possible to potentially create more new combinations of knowledge".

Both variety and depth of knowledge are important for technology-led organizations to absorb new knowledge more efficiently. Besides, given that innovation involves a process of establishing new linkages in the existing knowledge base, both variety and depth of the knowledge base in an organization can also facilitate the occurrence of innovations. Weak development of absorptive capacity becomes a barrier to the firm in recognizing technological opportunities and this in turn affects its ability to innovate and remain up to date with the latest developments and proactive in its innovative strategy.

According to Zahra and George (2002), absorptive capacity can be said to be a dynamic capability for a firm. It stands to reason that, if absorptive capacity is to be developed as a dynamic capability, sharing of knowledge with other firms (through alliances) as well as within the firm becomes an important process. Knowledge sharing can help firms to survive in the marketplace (through zero-order dynamic capabilities: Winter, 2003), build resources and capabilities (first-order dynamic capabilities: Teece et al., 1997), and develop the capability to build capabilities (second-order dynamic capabilities: Collis, 1994). In contrast to absorptive capacity, knowledge sharing is the process of transferring know-how from one individual or firm to another. Knowledge sharing can be explicit or implicit. Although the former can be represented in a way that others can assimilate it (i.e., it can be codified), the latter largely remains unavailable to others. It can only be used by the person in possession of such knowledge. 


\section{The Dynamics of Knowledge Sharing in the Biotechnology Industry: An Indian Perspective Tripurasundari Joshi}

A lot of the knowledge in the biotechnology sector is tacit and complex. Tacit knowledge "refers to the implicit and non-codifiable accumulation of skills that results from learning by doing" (Reed \& DeFillippi, 1990). It is recognized as a provider of sustainable competitive advantage because of its inherently non-copiable nature (Grant, 2013). However, this is more relevant in traditional industries where several firms may compete for the same product space with similar technologies. In the biotechnology industry, typically each firm is working with a unique technology and drug candidate, at least in the early development phases. Therefore, the challenge with tacit knowledge is different in this industry. Knowledge that is tacit is harder to codify and share, which can become a challenge for fruitful cooperation among alliance partners and project teams within the organization. It can lead to a poor conversion to innovations with commercial potential.

In terms of the complexity of knowledge inherent in the biotechnology sector, Simonin (1999) explains that it arises because "the number of interdependent technologies, routines, individuals, and resources linked to a particular knowledge or asset is high" and this "is expected to affect the comprehension of the totality of an asset and to impair its transferability". Thus, organizational routines play a key role in the sector by enabling biotechnology firms to "keep track of and hold on to their capabilities" (Cyert \& March, 1963), and learning processes greatly influence how such organizational routines are created (Zollo \& Winter, 2002).

At a firm level, knowledge sharing is the means for learning and creating routines to create the necessary capabilities. At the industry level, knowledge sharing can contribute in several ways to address the issue of reduced productivity in drug manufacturing firms, for instance, by designing more efficient testing processes that could improve quality and reduce the time required for regulatory approval. Knowledge sharing may also result in more effective drug protocols, that is, more effective research designs for testing drug candidates.

This is the paradox facing biotechnology firms in India: on the one hand, the nature of knowledge in biotechnology is difficult to transfer; on the other hand, transferability of knowledge is necessary to develop technological innovations, which are crucial for the growth of the sector in India. This paradox motivates the current research and leads to the question of how the firms in this sector are dealing with this paradox.

\section{Objectives and Methodology}

This study is an exploratory attempt to obtain a firmlevel view of the knowledge-sharing practices employed and the impediments they face because of the tacit and complex nature of the knowledge in biotechnology. The study also attempts to inductively derive the beliefs and reasoning behind the knowledge-sharing practices.

The two objectives of this study are:

1. To develop a preliminary understanding of firm-level knowledge-sharing practices in the biotechnology sector in India.

2. To understand impediments to knowledge sharing at the firm level, if any.

To reach these objectives, interviews were conducted with seven individuals with extensive scientific, managerial, entrepreneurial, or manufacturing experience in the biotechnology sector in India (Table 1). Due to the exploratory nature of the study, the interview subjects were identified as a judgement sample, meaning they were recruited for the interviews through personal contacts of the author, who has a background in the field. The judgement sample included respondents with a range of experience across the spectrum of the industry.

The interviews were conducted over a period of eight weeks. The interview protocol was semi-structured in the sense that key open-ended questions relating to the research objectives were framed in advance and used as a guideline for discussions. The questions related to the shared understanding of knowledge sharing in firms and its perceived relevance, formal and informal mechanisms employed in the firms to facilitate knowledge sharing, and the impediments faced with respect to sharing knowledge. Discussions on each question were carried out until saturation was reached and no further new points emerged. A total of 33 hours were spent on the discussions for the entire sample with an average time of 95 minutes. Probing was used extensively to facilitate an understanding of the reasoning behind the various practices. Extensive notes were taken and key points were confirmed with the respondents. The notes were integrated during analysis. Cooperation was enlisted after providing for conditions of anonymity and confidentiality. 


\section{The Dynamics of Knowledge Sharing in the Biotechnology Industry: An Indian Perspective Tripurasundari Joshi}

Table 1. Overview of the sample of respondents interviewed for this study

\begin{tabular}{ccl} 
Respondent & $\begin{array}{l}\text { Years of } \\
\text { Experience }\end{array}$ & Nature of Experience \\
\hline A & 15 & $\begin{array}{l}\text { Scientist in national laboratory and biopharmaceutical company; basic research; domestic } \\
\text { experience }\end{array}$ \\
\hline B & 9 & $\begin{array}{l}\text { Founder manager of a biotechnology startup; pharmaceutical development studies; domestic } \\
\text { experience }\end{array}$ \\
\hline C & 22 & Employee manager with a contract research and manufacturing company \\
\hline E & 16 & Scientist entrepreneur; contract research organization \\
\hline F & 26 & Pharmaceutical formulations; quality control; domestic business experience \\
\hline
\end{tabular}

G

19

Pharmaceutical company R\&D manager; international and domestic experience

\section{Findings on Knowledge-Sharing Dynamics}

\section{Facilitators of knowledge sharing}

The interviewees in this study felt that, in their experience, knowledge sharing is high in teams that involve one or more organizations as in the case of a drug development team consisting of members from a biotechnology firm and scientists involved in basic research in a university or national laboratory. This finding is expected given that alliances always bring in new knowledge which in itself is a motivator for knowledge sharing in a knowledge-based industry. Other instances of intense knowledge sharing happen in firms when teams pursue accreditation goals or are involved in active business development work to procure contracts. In these cases, there is a shared sense of purpose to achieve recognition for the competencies in a firm. Field notes reveal that knowledge sharing in many firms is normally tied to solving technical issues as they arise on projects. Intensive sharing occurs until a solution is reached, and the respondents reported that this activity added substantial value.

\section{Inhibitors of knowledge sharing}

Time pressure for project completion almost always reduces knowledge sharing. Situations where not completing projects on time could result in the confiscation of intellectual property rights (which is the case according to Indian regulations) further dis- courage sharing of knowledge that is not immediately useful to facilitate the project at hand. Knowledge sharing may be compromised when team members from within an organization come from different levels of the hierarchy. A major reason advocated was that tacit knowledge of people lower in the hierarchy may not be shared with people higher in the hierarchy because of perceived power distance between Indian employees. A certain caution would be exercised by juniors in the team in the presence of more experienced seniors, partly from a fear of their opinions not being accepted and partly out of a desire not to transgress boundaries of authority. The literature recognizes the existence of different influences on employee knowledge sharing activities, such as individual, organizational, and technology factors (Lee \& Choi, 2003). Firms in India could look at how organizational enablers could be put in place to overcome such cultural inhibitions.

Often, organizational members may not be aware of the depth of tacit knowledge available through other members until an opportunity arises from the environment. A case was quoted by respondent A about how a team member shared certain technical inputs with respect to stability studies in an interaction with the alliance partner. Through this incident, some members in the organization became aware of the team member as a locus of knowledge. 


\section{The Dynamics of Knowledge Sharing in the Biotechnology Industry: An Indian Perspective Tripurasundari Joshi}

Notably, the findings show that, although knowledge sharing is high in alliances, when the Indian firm has several alliances in place and when the same team members within the firm are involved in projects with more than one alliance partner, knowledge sharing goes down. In such cases, just enough knowledge sharing happens to achieve the immediate project goal. Having many alliances compromised knowledge sharing because more time was spent on the administrative aspects of managing the various alliances and multiple projects have to be completed as per given deadlines. This problem is compounded when the performance depends on the number of alliances (at the firm level) and the number of projects completed (at the individual level).

\section{Founders' background}

Founding members of firms who have had scientific careers, either in laboratories or pharmaceutical biotechnology companies, before taking up entrepreneurship tend to take a personal interest in setting up formal means for knowledge sharing and actively promote them among the technical staff. An important observation from the interviews is that founders of firms who hail from a non-pharmaceutical biotechnology background are more preoccupied with business development issues related to funding, alliance management, and the like. They may not actively or formally sponsor knowledge-sharing initiatives. It is largely left to individual scientific personnel to do it as they see fit.

\section{Formalizing knowledge sharing}

The respondents were divided in their opinions about formalizing knowledge sharing in organizations. As understood by the scientists, formalization would include mechanisms such as holding regular in-house seminars and workshops, writing whitepapers and reports as learning outcomes from completed projects, creating databases, and so on. In several cases, attempts to formalize knowledge sharing were seen to be artificial and not significantly contributing to business outcomes. They add value to individual-level knowledge and confidence, but it is difficult to trace their contribution to innovative project outcomes.

Arguments in favour of setting up formal mechanisms included codification of knowledge and an "awareness about the loci of expertise and the levels of expertise within the organization" (Respondent E). That is to say, the firm as a team would become aware about which individuals possessed what kind of knowledge and its level of sophistication. In the pharmaceutical-biotech- nology context, this could mean experience in using a particular technique or richer troubleshooting when confronted with unexpected laboratory results. Further, it would enable some form of codification through the creation of troubleshooting manuals or reports that could be placed in the general repository for access by the team. Although almost all the respondents agreed on the near impossibility of codifying all tacit knowledge, they also felt that "any codification efforts, however meagre, are likely to contribute to overall productivity in projects" (Respondent F).

There was also a strong opinion about allowing knowledge sharing to happen on a need basis in projects. The reasoning was that knowledge sharing is more "accurate, complete, and rich" (Respondent A) when it happens as part of a project with a specific mandate because team members take the process seriously and they want the project outcomes to be positive. This attitude gives rise to an intrinsic commitment that makes a qualitative difference in the content and the way knowledge is shared. Also, the recipients are more engaged and receptive to the knowledge being transferred. A further reasoning was that knowledge acquired in such a situation is likely to be retained better, albeit as tacit in nature.

Knowledge sharing as part of routines set up by the management, such as regular workshops and other forms of supervised mechanisms, were not welcome to some of the scientists who preferred learning on a need basis and who felt it was difficult to anticipate in advance what they needed to know. Indeed, there was so much diversity in knowledge in this sector that "one could not assimilate knowledge in the expectation that someday in the future it could come in useful" (Respondent B). However, the chances of that knowledge becoming obsolete could not be ruled out. On closer probing, it was revealed that, in complex projects, as in projects that were new to the firm, it was difficult to anticipate the expertise that would be required.

What one respondent said about their project team was revealing. One of their project teams have worked successfully on several projects, and "their level of technical expertise and their comfort and understanding of one another all works together well" (Respondent G). When asked whether they could identify what worked for the team, the manager responded that it had not occurred to them to ask that question and "anyways it does not matter really, so long as the team continues to deliver on our innovation goals". It appears that the 


\section{The Dynamics of Knowledge Sharing in the Biotechnology Industry: An Indian Perspective Tripurasundari Joshi}

firm is happy to facilitate and allow what works to keep working without trying to impose a structure based on analysis and reflection. However, all respondents agreed on the utility of formal mechanisms such as regular email or newsletter updates on information about new projects, grants, discoveries and industry news, and so on, because this helped them to remain abreast of developments within the company and industry.

It can then be broadly inferred that the respondents are distinguishing between "know what" and "know how". Among the various mechanisms for knowledge transfer, apprenticeships and project-based deep interactions are considered by the respondents to be both effective and necessary for sharing know how.

One practice reported by one of the respondents in a firm that he worked with in the initial years of his career involved appointing an expert who was typically someone with multiple domain expertise and long tenure with the organization to support in responding to queries from less experienced team members. This practice worked well in the normal course except in situations where the investment of time and effort exceeded the perceived acceptable levels by the expert. In such cases, formal incentivization for the expert is required to keep the practice effective. However, in this particular case, giving a monetary incentive did not work as well because of the reduced gap in expertise between the expert and others and the subsequent loss in knowledge power acted as a disincentive.

Some instances of judgement-based knowledge sharing that were shared by the respondents involve a certain amount of discretionary evaluation of technical options or situations. In these cases, the knowledge is deeply personal and intuitive. Two considerations prevent knowledge sharing in these cases. One is the fear of sharing away the very know how that distinguished the knowledge holder as an authority in the domain, and the other is that there may be counter arguments about its veracity.

Team members in a project typically also have some parochial concerns. As one respondent who has grown from a purely technical career path to a managerial one in the pharmaceutical biotechnology sector puts it very strongly, non-routine sharing of deep knowledge involving time and effort and which can make a lasting impact on the realized absorptive capacity needs to be wired into the compensation and reward systems in the firm. It is additional effort that needs to be recognized as such.
A major impediment to knowledge sharing identified by a scientist respondent is the technical variety in projects undertaken by a firm. If the skills or expertise are not complementary, it would hinder meaningful sharing of know how. Often in complex pharmacokinetic decision-making studies, knowledge sharing is slow and tentative. As pointed out by a respondent, this may be the case sometimes even in not so complex studies but where the team has no prior execution experience. This reflects the theoretical observation made in literature. The degree of knowledge codifiability is of importance in determining the speed of the knowledge transfer (Zander \& Kogut, 1995). Lack of time and preoccupation with administrative work is another reason cited for poor knowledge sharing in some quarters. In a growing organization, only knowledge that concerns the survival aspects of the firm is shared willingly. These patterns are formalized as routines and represent what is referred to as zero-order capabilities. Most firms have these in place.

Monitoring of knowledge sharing differs across the value chain. In the product development phase, when familiarity with the candidate drug is weak, monitoring is tighter and formalization of sharing is seen. This is not the case in areas such as repeat clinical trials requiring only minor modifications to procedures. Knowledge sharing as part of routines such as clinical procedures are said to happen smoothly and efficiently. A more lasting impact on knowledge sharing, especially the tacit form, is expected to happen by building a culture of sharing in organizations. However, this takes time and commitment and could happen organically as biotechnology firms evolve.

A notable observation from the personal experience of a respondent refers to the failure of a knowledge-sharing initiative in his current organization (a clinical research organization) because the recipients and the provider did not agree on the knowledge-sharing tools to be used in a specific knowledge-transfer exercise. Whereas the provider was willing to codify it in the form of whitepapers, the recipients were more comfortable with an apprenticeship program that the provider felt was too time consuming given his work commitments.

Other impediments mentioned during the course of the interviews include both organizational and personal or individual concerns. If systematic knowledge sharing is done on a regular basis, one significant organizational concern is employees leaving for better prospects. Against the background of a shortage of 


\section{The Dynamics of Knowledge Sharing in the Biotechnology Industry: An Indian Perspective Tripurasundari Joshi}

technical talent in the industry, this is an avoidable risk. Finally, although active knowledge sharing may not always be formally rewarded, its absence as part of workflow requirements are brought to the notice of the concerned team members, discussed, and rectified. This practice reflects the awareness that the Indian biotechnology firms have about being low on the learning curve given that they are in what is still a young industry.

As to the question on how tacit knowledge in individuals benefits the firm, the respondents opined that its manifestation happens in several ways. Those possessing it are able to process available data and "recognize patterns in it which others who lack that knowledge cannot" (Respondent B). Also, they are able to take quicker judgements or decisions that turn out right at the end of the project.

When a new project is obtained by a company, a key person is involved directly with the alliance partner. This person later transfers the knowledge acquired to other members in the organization. The richness of knowledge transfer is compromised because a lot of the tacit part cannot be transferred. To overcome this limitation, the key person is involved in all processes or activities, which reduces the versatile use of such resource persons. A solution used by organizations is to involve more members. A possible solution tried out by some firms is to appoint more key people to do the knowledge assimilation and transfer. In such cases, the effectiveness of knowledge transfer also depends on the collective assimilation by the group. Group dynamics during assimilation and transfer become important determinants of the extent and success of the transfer process.

Although involving a larger group would ensure that knowledge is dispersed in the firm, a shortage of human resources often acts as a barrier, which is a reflection of the macro-level constraint in the Indian biotechnology sector. Knowledge sharing is also hindered by the businesslike approach to problem solving adopted by some founder CEOs who do not have a science background. Scientists would prefer to complete the knowledge assimilation and sharing process, thereby bringing it to its logical conclusion so that the phenomenon in question is thoroughly understood. To achieve this, most of the respondents agreed that the means to achieve genuine transfer of knowledge is through observation, which can be facilitated through apprenticeships and mentoring.
A final but important point to emerge was the realization that knowledge sharing is also not very effective from an organizational point of view until individual technical staff fully understand the unique needs of their firm and have adapted their individual expertise to achieve the firm's goals. A hindering factor mentioned is a lack of a sufficient number of projects for them to work on.

Given that knowledge management as a discipline is still evolving in the Indian biotechnology space, each firm needs to assess the right mix of codification and network sharing that would be ideal given their firm's goals and strategies.

\section{Conclusions}

This study has provided an initial understanding and the rationale for the dynamics of knowledge sharing in the biotech sector in the Indian context. Knowledge sharing appears to be an idiosyncratic process for every firm given their level of current expertise and their strategies to achieve a competitive position in the market. Apparently, knowledge sharing is more free flowing when it spans organizational boundaries than when it spans organizational hierarchies. Barriers to knowledge sharing are more than the facilitating factors, as the findings reveal. This may be in keeping with the prominence of tacit knowledge in the sector. Experiential learning is important since knowledge is tacit and the tools which are felt to be effective include mentoring and apprenticeships.

To understand the implications, the findings of this exploratory study need to be related to the theoretical observations made in the literature regarding high-technology, dynamic, and knowledge-intensive industries. Eisenhardt (1989) refers to "high velocity" dynamic markets in which dynamic capabilities take on unique characteristics. They are experiential, iterative, and less predictable. The firms in such industries typically respond to these characteristics through the use of real-time information, intensive communication, knowledge creation, experimentation, prototyping, crossfunctional teams, and multiple alternatives that are cross-functional. These strategies help to manage risk and build competitive advantage. However, the key challenges faced by firms are continuous knowledge transformation and its continuous erosion because of lack of structure. The levels of ICT usage appears patchy based on first impressions from this study. A more detailed study on the types and levels of ICT usage in different 


\section{The Dynamics of Knowledge Sharing in the Biotechnology Industry: An Indian Perspective Tripurasundari Joshi}

segments (e.g., clinical research, vaccines) could be useful. A segment-level approach is suggested because the extent of knowledge codifiability could differ across segments.

More insights are needed to understand how the dynamic capability of absorptive capacity is being operationalized in the Indian context. Possible answers to this would involve development of a suitable culture and setting up systems and structure to facilitate this. Future research using a multiple case design could look at these issues more closely for a deeper understanding.

\section{About the Author}

Tripurasundari Joshi is an Assistant Professor in the marketing area at the Institute of Management at Nirma University in Ahmedabad, India. She holds postgraduate qualifications in science and business administration. She has 13 years of corporate experience in business development, corporate planning, and management consultancy in the managerial cadre. She has carried out numerous research and business advisory assignments for large corporate clients. She has also worked on technology status and technology market assessment studies for the Government of India, and she has executed several projects funded by the World Bank and Asian Development Bank. She has received grants for working on social projects sponsored by national institutes of repute such as the Indian Space Research Organization. Since 1999, she has been involved as a fulltime core faculty member in the Marketing area of Business Management and has been active in institution-building activities in various academic administrative capacities. She has authored several books, monographs and technical notes and has presented and published research at national and international conferences. She has also visited universities and industry associations in Australia, China, Singapore, and Hong Kong for research and business interactions.

\section{References}

Aggrawal, A. 2007. India's Knowledge Process Outsourcing (KPO) Sector: Origin, Current State, and Future Directions. Schaffhausen, Switzerland: Evalueserve.

ABLE. 2017. White Paper on India's Biotechnology StartUp Ecosystem. Bangalore, India: Association of Biotechnology Led Enterprises (ABLE).

Bains, W. 2004. Failure Rates in Drug Discovery and Development: Will We Ever Get Any Better? Drug Discovery World, 5(4): 9-19.

Bierly III, P. E., Damanpour, F., \& Santoro, M. D. 2009. The Application of External Knowledge: Organizational Conditions for Exploration and Exploitation. Journal of Management Studies, 46(3): 481-509.

http://doi.org/10.1111/j.1467-6486.2009.00829.x

Carayannis, E. G., Popescu, D., Sipp, C., \& Stewart, M. 2006. Technological Learning for Entrepreneurial Development (TL4ED) in the Knowledge Economy (KE): Case Studies and Lessons Learned. Technovation, 26(4): 419-443.

https://doi.org/10.1016/j.technovation.2005.04.003

Cohen, W. M., \& Levinthal, D. A. 1990. Absorptive Capacity: A New Perspective on Learning and Innovation. Administrative Science Quarterly, 35(1): 128-152.

http://doi.org/10.2307/2393553

Collis, D. J. 1994. Research Note: How Valuable are Organizational Capabilities? Strategic Management Journal, 15(2): 143-152.

http://doi.org/10.1002/smj.4250150910

Cyert, R. M., \& March, J. G. 1963. A Behavioral Theory of the Firm. New York: Prentice Hall.

Dickson, M., \& Gagnon, J. P. 2004. Key Factors in the Rising Cost of Drug Discovery and Development. Nature Reviews Drug Discovery, 3: 417-429.

http://doi.org/10.1038/nrd1382

Edwards, M. G., Murray, F., \& Yu, R. 2003. Value Creation and Sharing Among Universities, Biotechnology and Pharma. Nature Biotechnology, 21: 618-624.

http://doi.org/10.1038/nbt0603-618 


\section{The Dynamics of Knowledge Sharing in the Biotechnology Industry: An Indian Perspective Tripurasundari Joshi}

Eisenhardt, K. M. 1989. Making Fast Strategic Decisions in High-Velocity Environments. Academy of Management Journal, 32(3): 543-576.

http://doi.org/10.2307/256434

Frew, S. E., Kettler, H. E., \& Singer, P. A. 2008. The Indian and Chinese Health Biotechnology Industries: Potential Champions of Global Health? Health Affairs, 27(4): 1029-1041.

http://doi.org/10.1377/hlthaff.27.4.1029

Grant, R. M. 1996. Towards a Knowledge-Based Theory of the Firm. Strategic Management Journal, 17(S2): 109-122.

http://doi.org/10.1002/smj.4250171110

Harlow, H. F. 1949. The Formation of Learning Sets. Psychological Review, 56(1): 51-65.

http://psycnet.apa.org/doi/10.1037/h0062474

Huang, H. C. 2011. Technological Innovation Capability Creation Potential of Open Innovation: a Cross-Level Analysis in the Biotechnology Industry. Technology Analysis \& Strategic Management, 23(1): 49-63.

https://doi.org/10.1080/09537325.2011.537105

IPI. 1970. The Patents Act, 1970. Mumbai: Intellectual Property India (IPI), Government of India.

Keller, T. H. 2001. Challenges and Opportunities in the 21st Century. Current Opinion in Chemical Biology, 5(4): 349-351.

https://doi.org/10.1016/S1367-5931(00)00213-1

Lee, H., \& Choi, B. 2003. Knowledge Management Enablers, Processes, and Organizational Performance: An Integrative View and Empirical Examination. Journal of Management Information Systems, 20(1): 179-228.

https://doi.org/10.1080/07421222.2003.11045756

Miller, H. I. 2002. As Biotech Turns 20... Nature Reviews Drug Discovery, 1: 1007-1008.

https://doi.org/10.1038/nrd965

Phene, A., Fladmoe-Lindquist, K., \& Marsh, L. 2006. Breakthrough Innovations in the U.S. Biotechnology Industry: The Effects of Technological Space and Geographic Origin. Strategic Management Journal, 27(4): 369-388.

https://doi.org/10.1002/smj.522
Powell, W. W. 1996. Inter-Organizational Collaboration in the Biotechnology Industry. Journal of Institutional and Theoretical Economics, 152(1): 197-215.

http://www.jstor.org/stable/40751919

Quinn, J. B. 2000. Outsourcing Innovation: The New Engine of Growth. Sloan Management Review, 41(4): $13-28$.

Reed, R., \& DeFillippi, R. J. 1990. Causal Ambiguity, Barriers to Imitation, and Sustainable Competitive Advantage. The Academy of Management Review, 15(1): 88-102.

http://doi.org/10.5465/AMR.1990.4308277

Simonin, B. L. 1999. Ambiguity and the Process of Knowledge Transfer in Strategic Alliances. Strategic Management Journal, 20(7): 595-623.

http://doi.org/10.1002/(SICI) 1097-

0266(199907)20:7<595::AID-SMJ47>3.0.CO;2-5

Teece, D., Pisano, G. P., \& Shuen, A. 1997. Dynamic Capabilities and Strategic Management. Strategic Management Journal, 18(7): 509-533.

http://doi.org/10.1002/(SICI) 1097-

0266(199708) 18:7<509::AID-SMJ882>3.0.CO;2-Z

The Hindu. 2011. Revenues of Biotech Sector surge to $\$ 4$ billion. The Hindu, June 18, 2011. Accessed January 15, 2018:

http://www.thehindu.com/business/Industry/revenues -of-biotech-sector-surge-to-4-

billion/article2115953.ece

Winter, S. G. 2003. Understanding Dynamic Capabilities. Strategic Management Journal, 24(10): 991-995.

http://doi.org/10.1002/smj.318

Zahra, S. A., \& George, G. 2002. The Net-Enabled Business Innovation Cycle and the Evolution of Dynamic Capabilities. Information Systems Research, 13(2): 147-150.

https://doi.org/10.1287/isre.13.2.147.90

Zander, U., \& Kogut, B. 1995. Knowledge and the Speed of the Transfer and Imitation of Organizational Capabilities: An Empirical Test. Organization Science, 6(1): 76-92.

https://doi.org/10.1287/orsc.6.1.76 


\section{The Dynamics of Knowledge Sharing in the Biotechnology Industry: An Indian Perspective Tripurasundari Joshi}

Zollo, M., \& Winter, S. G. 2002. Deliberate Learning and the Evolution of Dynamic Capabilities. Organization Science, 13(3): 339-351.

https://doi.org/10.1287/orsc.13.3.339.2780

Citation: Joshi, T. 2017. The Dynamics of Knowledge

Sharing in the Biotechnology Industry: An Indian

(cc) BY

Perspective. Technology Innovation Management

Review, 8(1): 5-15.

http://doi.org/10.22215/timreview/1129

Keywords: biotechnology, knowledge sharing, tacit

knowledge, India, absorptive capacity 


\section{Academic Affiliations and Funding Acknowledgements}

Canadà
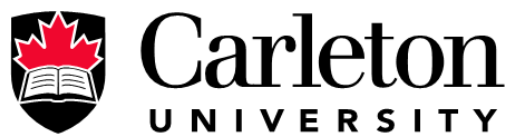

U N I V E R S I T Y

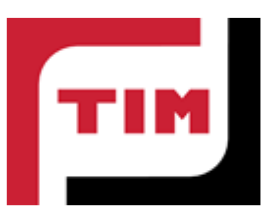

The Federal Economic Development Agency for Southern Ontario (FedDev Ontario; feddevontario.gc.ca) is part of the Innovation, Science and Economic Development portfolio and one of six regional development agencies, each of which helps to address key economic challenges by providing regionallytailored programs, services, knowledge and expertise.

- The TIM Review receives partial funding from FedDev Ontario's Investing in Regional Diversification initiative.

Technology Innovation Management (TIM; timprogram.ca) is an international master's level program at Carleton University in Ottawa, Canada. It leads to a Master of Applied Science (M.A.Sc.) degree, a Master of Engineering (M.Eng.) degree, or a Master of Entrepreneurship (M.Ent.) degree. The objective of this program is to train aspiring entrepreneurs on creating wealth at the early stages of company or opportunity lifecycles.

- The TIM Review is published in association with and receives partial funding from the TIM program. 